\title{
LA INCERTIDUMBRE DEL TEXTO EN LA EXPERIENCIA JURÍDICA ROMANA. A PROPÓSITO DE D.1,2,2,1-3
}

\author{
UNCERTAINTY OF TEXT IN THE EXPERIENCE OF ROMAN LAW: ON \\ D. $1,2,2,1-3$
}

\section{Patricio Lazo ${ }^{2}$}

\begin{abstract}
RESUMEN: Los problemas que trae aparejados la incerteza de textos normativos es el centro de este trabajo. El problema es asumido desde la perspectiva de las condiciones de posibilidad de un sistema jurídico carente de uno o más textos en los cuales basar las decisiones. La materia sobre la cual recae el análisis corresponde a la experiencia jurídica romana, específicamente los hechos narrados por Pomponio en D.1,2,2,1, que refiere los problemas que supuso la inexistencia de textos normativos durante la época monárquica y su solución, a través de la compilación conocida como ius Papirianum.
\end{abstract}

Palabras clave: Pomponio, incerteza del derecho, derecho romano, leyes regias, ius incertum

ABSTRACT: The problems linked to the uncertainty of legal texts are the main issue of the article. The problem focuses on the impact on the legal system of the lack of legal texts to support decisions. The matter of analysis lays on the roman legal experience, more specifically on the facts described by Pomponius on D.1,2,2,1. This text reports the problems derived from the inexistence of legal texts along the monarchy period and its solution, through a statutes collection known as ius Papirianum.

Key words: Pomponius, uncertainty of law, Roman law, roman monarchy statutes, ius incertum.

\section{LA INCERTEZA DEL TEXTO COMO PROBLEMA}

Sería difícil describir en un espacio relativamente breve la importancia que los textos revisten para el desarrollo del derecho o, mejor dicho, para la ciencia y la práctica que se desarrollan en torno a ellos. Aunque los sistemas jurídicos suelen admitir la vigencia de costumbres como una de sus partes integrantes, el peso que llegan a tener no es equiparable al de los textos, al punto que podría afirmarse, sin temor a equivocarse, que estos constituyen la principal base sobre la cual se construyen y perfeccionan los sistemas jurídicos.

La existencia o inexistencia de determinados textos - preocupación que bien podría extenderse a su número, pero con mayor razón a su contenido- puede llegar a constituir un problema crítico del sistema jurídico, en cuanto pone a prueba su capacidad para generar sentido; esto último pone en riesgo, además, su relevancia. Entiendo que un sistema jurídico es capaz de generar sentido cuando permite desarrollar una específica función en torno a

1 Este trabajo forma parte del proyecto FONDECYT No 1120606, así como también del proyecto Anillo-CONICYT soc-1111 y corresponde a una versión con notas de la comunicación leída en las XXV Semanas de Estudios Romanos, Valparaíso 2-6 de septiembre de 2013.

2 Profesor de Derecho Romano, Pontificia Universidad Católica de Valparaíso. 
sí mismo: aquella consistente en seleccionar una posibilidad de entre varias, diferenciando, de este modo, aquello que ha de calificarse conforme a derecho, de aquello que no ${ }^{3}$. Esta función la desarrolla a través de la producción de textos en que los especialistas -llámense estos juristas, jueces o prácticos- describen el sentido de otros textos, proceso este que se denomina interpretación. En la medida que existen textos hay interpretación y en cuanto esta constituye producción de comunicación, el sistema jurídico se mantiene vivo. La razón es sencilla: la existencia de aquellos textos jurídicos a partir de los cuales se desarrollará la interpretación está estrechamente relacionada con problemas que afectan a la sociedad y que reclaman una respuesta. Así entendido, un problema de carácter jurídico consiste en una pregunta cuya respuesta se espera encontrar en aquellos textos. El sistema jurídico, a pesar de mantener siempre un alto grado de autonomía en su funcionamiento ${ }^{4}$, permanece atento a los problemas de su entorno ${ }^{5}$, en cuanto ellos tienen la capacidad para provocar operaciones de comunicación, reacciona proporcionando respuestas. En la medida en que estas dan una solución adecuada, la operatividad del sistema jurídico contribuye a la reducción de la complejidad de su entorno y, de paso, conserva un alto grado de relevancia.

Por consiguiente, los problemas surgen cuando los textos que deben ser interpretados no existen, o bien cuando, a pesar de existir, su conocimiento, comprensión, o estatus (por ejemplo, su vigencia) plantean dificultades tales que ninguna respuesta creada a su alero satisface la necesidad que reclama una respuesta. De este modo, aparece en el horizonte la necesidad de crear textos, de forma de eliminar inseguridades por la vía de encontrar en la interpretación de estos las respuestas a diferentes necesidades. Es precisamente a esta clase de problemas a lo que se designa en este trabajo con la expresión 'incertidumbre'.

Cuanto se acaba de esbozar ha sido tratado, al menos parcialmente, en la romanística del siglo XX. Lelio Lantella se refirió a él hace ya varios años ${ }^{6}$ y Cannata realizó un aporte a la discusión al indagar la medida en que el ius controversum -esto es, la oposición entre respuestas de diferentes juristas acerca de un mismo asunto- constituía una hipótesis de incer-

\footnotetext{
${ }^{3}$ Luhmann (1998) p. 28, afirma que "el sentido comporta siempre focalizar la atención sobre una posibilidad entre muchas". Esta noción de sentido es muy coherente con las ideas que en la metodología jurídica tenemos acerca del mismo, en particular, cuando se utiliza en relación con una norma. Así, por ejemplo, la conocida expresión medieval sensus legis, que GUZMÁn BRITO (2011) p. 46, describe como sigue: "El sensus (mens, sententia, intellectus) legis no es un elemento ostensible, en el modo que sí lo es su tenor literal, por lo cual resulta necesario construirlo. El instrumento idóneo para la construcción del sentido legal es la ratio legis, o fin objetivo de sus prescripciones (causa finalis). La ratio legis es la que define, pues, las verdaderas hipótesis de aplicación de una ley". Acerca de qué puede entenderse sobre "sentido de la ley", véase GuZmán Brito (2007) p. 127 ss. A su vez, la dicotomía Derecho/no-Derecho ("Recht/Unrecht) es el esquema de distinción (binario) que la teoría de sistemas reconoce al derecho: véase vid. LuHMANn (1987) p. 121 ss.; LuHMANn (1995) p. 61; LuHMANn (2005) p. 116. Sobre las dificultades para traducir la expresión alemana, puede verse la prevención al respecto de Torres Narrafate, en LuHMANN (2005) p. 81.

${ }^{4}$ Me refiero a aquello que la teoría de sistemas de matriz luhmanniana denomina 'clausura operacional', entendido como una suerte de aislamiento del sistema respecto del entorno, pero que no excluye la comunicación con este en virtud del denominado 'acoplamiento estructural', que mantiene la cohesión del sistema al entorno. Todo lo cual es consecuencia de su carácter autopoiético: véase vid. Losano (2002) p. 238 ss.

5 Se trata del acoplamiento estructural del que se hablaba en la nota anterior, merced al cual el sistema jurídico mantiene un contacto, pero no dependencia, con respecto a los demás subsistemas, que operan para él a modo de entorno.
}

${ }^{6}$ Lantella (1987) pp. 223 ss. 
tidumbre. Su respuesta, basada en un texto de Pomponio ${ }^{7}$, no puede ser más sorprendente, así como exacta: "Siccome la certezza é una delle qualità che il diritto asume nel suo migliorarsi, il ius controversum diventa pure condizione della certezza del diritto" ${ }^{8}$. Y no deja de constituir todo ello una paradoja, por cuanto al depender las sentencias judiciales de las opiniones de los juristas, en la misma medida en que estas sean controvertidas, vuelven las decisiones de aquellos menos previsibles, lo que imprime a la situación un importante grado de incertidumbre?

En este orden de ideas este trabajo examina algunos supuestos de incertidumbre textual, acotando los ejemplos de esta breve indagación a aquellos que proporciona el derecho romano ${ }^{10}$. Centraré mi atención en un ejemplo de incertidumbre causada por la ausencia de textos, de modo de avanzar hacia los mecanismos conforme a los cuales dicha incertidumbre toca a su fin. El texto elegido es D.1,2,2,1 y corresponde al jurista romano de la primera mitad del siglo II d.C., Pomponio.

\section{SINE LEGE CERTA SINE IUS CERTO}

El Enchiridium es la obra de Pomponio ${ }^{11}$ de contenido semejante al de un manual, en que se expone una extensa historia del derecho romano. En cuanto relato histórico, intenta abarcar desde los albores de la historia romana y, por tal motivo, dedica una de sus partes al derecho de la época de la monarquía. En esta parte Pomponio se detiene en la descripción del problema del conocimiento de la ley y al hecho de cómo una sencilla fijación de normas jurídicas ${ }^{12}$, que sería conocida por la posteridad como ius Papirianum, contribuyó, al menos por un tiempo a resolver ${ }^{13}$ :

D.1,2,2,1 (Pomp. lib. sing. enchr.) "En el comienzo de nuestra ciudad el pueblo se constituyó sin ley cierta, sin derecho cierto, y todas las cosas se gobernaban por el poder de los reyes. (2) Después de crecer algo la ciudad, se sabe por tradición que el mismo Rómulo dividió al pueblo en treinta partes que llamó curias porque atendía al cuidado de la república, según los pareceres de aquellas partes, y así él mismo propuso al pueblo algunas leyes curiadas; también así lo hicieron los reyes siguientes. Todas estas leyes, se hallan reunidas en

D.1,2,2,13:...constare non potest ius, nisi sit aliquis iuris peritis, per quem possit cottidie in melius produci. [... el derecho no puede conservarse, si no es a causa de algún jurista, gracias a quien puede generarse y mejorar cotidianamente].

8 Cannata (2003) p. 43.

9 A juicio de CANnATa (2003) p. 44, durante la época pontifical la incerteza no dependía del carácter controversum del derecho jurisprudencial, sino que esta clase de incertidumbre es más propia de la jurisprudencia laica.

10 Véase también Bona (1997) pp. 101 ss.

11 La principal obra de Pomponio fueron sus comentarios ad edictum, ad Q. Mucium y ad Sabinum, que representan, en opinión de KUnKel y SCHERMAier (2001) p. 158, un resumen de la obra de la jurisprudencia romana hasta su época.

12 Según Paoli (1946-1947) p. 157 s., se trataba de una colección de normas y no de una obra de comentarios, lo que se seguiría de la frase del mismo Pomponio en el sentido que "leges quasdam... extant in libro Sexti Papirii". BRETONe (2011) p. 269 s. cree que no es inverosímil la hipótesis de una colección de leges regiaeleges regiae y, en cuanto a su contenido, afirma que ellas son de carácter sacro. La discusión más reciente en Bujulic (1998) 89 ss.

13 Las hipótesis que cuestionan la autoría de Pomponio, o la autenticidad de la tradición de la que nuestro jurista da cuenta, no son objeto de análisis. En la desestimación de tales tesis seguimos a BrETONE (2011) p. 269. 
un libro de Sexto Papirio, uno de los hombres prominentes en los tiempos de Tarquino el Soberbio, hijo de Demarato de Corinto. Ese libro, como se ha indicado, ha sido llamado 'Derecho Civil Papiriano' no porque Papirio agregara algo suyo, sino porque redujo a unidad leyes aprobadas sin orden alguno. (3) Al ser expulsados los reyes por una ley tribunicia, todas estas leyes desaparecieron y el pueblo romano comenzó por segunda vez a hacer uso de un derecho incierto y de las costumbres antes que de la ley, y todo ello ocurrió por casi veinte años" 14 .

El relato de Pomponio puede ser analizado descomponiéndolo en cuatro partes, cada una de las cuales se refiere a un momento histórico específico. El primero corresponde al de inexistencia de un texto conforme al cual actuar; el segundo, a la etapa de generación de textos jurídicos; el tercero, a la ordenación de los textos hasta ese instante acumulados por medio de la composición de un solo corpus, y, finalmente, el momento de la pérdida de vigencia de dicho corpus y el consiguiente advenimiento de un nuevo período de incertidumbre. Me referiré, detenidamente, a cada una de estas partes del relato.

Un primer momento histórico, como se adelantó, se caracteriza por la ausencia de textos jurídicos conforme a los cuales los ciudadanos pudieran llevar adelante actos cotidianos. Pomponio señala que el pueblo celebraba actos "sine lex certa, sine iure certo". Sería tentador sostener que lo que no existían eran normas, pero no sería del todo preciso. Estas sí existían, el problema es que no constaban en textos, lo que explicaría su incertidumbre. Es decir, las normas acerca de cómo actuar consistían en decisiones del rey, desde luego, limitadas a determinados casos: "omniaque manu a regibus gubernabantur"15.

Debe aún agregarse que las expresiones lex y ius, cuya incerteza caracteriza este período, consisten en conceptos diferentes, que el mismo Pomponio, en otro pasaje de este mismo fragmento (D.1,2,2,5), aclara. Así, al hablar de ius afirma: "Haec disputatio et hoc ius, quod sine scripto uenit compositum a prudentibus, propria parte aliqua non appellatur, ut ceterae partes iuris suis nominibus designantur, datis propriis nominibus ceteris partibus, sed communi nomine appellatur ius ciuile" ${ }^{16}$. Pomponio, por consiguiente, no utiliza al azar ambos conceptos, sino que quiere significar algo obvio: no había leyes ni tampoco interpretación

\footnotetext{
${ }_{14}$ D. 1,2,2,1-3 (Pomp. lib. sing. enchr.) Et quidem initio civitatis nostrae populus sine lege certa, sine iure certo primum agere instituit omniaque manu a regibus gubernabantur. (2) Postea aucta ad aliquem modum civitate ipsum Romulum traditur populum in triginta partes dividisse, quas partes curias appellavit propterea quod tunc rei publicae curam per sententias partium earum expendiebat. Et ita leges quasdam et ipse curiatas ad populum tulit: tulerunt et sequentes reges. Quae omnes conscriptae exstant in libro Sexti Papirii, qui fuit illis temporibus, quibus Superbus Dematarati Corinthii filius, ex principalibus viris. Is liber ut diximus, appellatur ius civile Papirianum, non quia Papirius de suo quicquam ibi adiecit, sed quod leges sine ordine latas in unum composuit. (3) Exactis deinde regibus lege tribunicia omnes leges hae exoleverunt iterumque coepit populus Romanus incerto magis iure et consuetudine aliqua uti quam per latam legem, idque prope viginti annis passus est.

${ }^{15}$ Llama la atención que en el texto se hable de reyes anteriores a Rómulo; ello sería abiertamente contradictorio con el hecho de que, según el relato legendario, aquel fue el primer rey de Roma. No podemos extendernos sobre este problema, pero sí es posible indicar que una hipótesis que permitiría dotar de sentido a la afirmación consistiría en diferenciar dos etapas en la época del reinado de Rómulo; una inicial, no legiferante, y una segun$\mathrm{da}$, en que se dictan leyes.

${ }^{16}$ Trad.: "Esta discusión y este derecho, que sin estar escrito vino a ser creado por los juristas, no se designa por una parte especial del mismo, como se designan por sus nombres determinadas partes del derecho, siéndole dado a cada parte tener su propio nombre, sino que se llama comúnmente, derecho civil”.
} 
de las mismas, aunque normas -esto es, decisiones- $\mathbf{s}^{17}$. De este modo, la incerteza acerca de leyes y de su interpretación es equivalente a la ausencia de textos jurídicos, es decir, de fijaciones, una de cuyas muchas características es -en el caso de las leyes- que constituyen una norma de destinatario genérico, lo que la diferencia de una decisión, en que predomina la singularidad de la respuesta. Lleva razón en esto Lantella, cuando afirma que la certeza del derecho es un bien político de valor primario, en cuanto la antítesis ley/no-ley es una forma de expresar la antítesis tirano/buen-rey ${ }^{18}$.

La segunda etapa coincide con la promulgación de leyes: "Et ita leges quasdam et ipse curiatas ad populum tulit: tulerunt et sequentes reges”, práctica que habría iniciado Rómulo y que habrían continuado los reyes que le sucedieron. Estos textos son conocidos en la historiografía romanística como leges regiae y aunque la mención a los comicios haría pensar en una activa participación de estos en su aprobación ${ }^{19}$, ello es hasta el día de hoy discutido ${ }^{20}$. Comoquiera que sea, es un hecho que la actividad legiferante de los reyes vino a poner término a la situación de cuando menos uno de los extremos de la incertidumbre, el provocado por la falta de lex certa ${ }^{21}$. Por ahora creo necesario poner de relieve que, al ser continuada por los sucesivos monarcas la promulgación de leyes, podría conjeturarse el mantenimiento de al menos un buen número de estas durante un arco de tiempo cercano a los doscientos años. Sería aventurado hipotetizar siquiera un número aproximado de tales leyes, pero cualquiera haya sido este, parece probable la existencia de circunstancias que hayan dificultado su conocimiento y, con ello, afectado su certidumbre. Una conjetura en tal dirección tendría la virtud de explicar el sentido del tercer momento histórico relatado por Pomponio.

La tercera etapa corresponde a la labor de sistematización de la legislación producida en toda esta época. En su breve relato Pomponio hace tres importantes referencias a la obra de Papirio, de las cuales es posible extraer algunas de sus características: primeramente, sostiene que en ella "omnes (sc. leges) conscriptae exstant". Pomponio se vale de la voz conscripta -en plural: conscriptae - para dar una primera idea. Aquella es el participio de pretérito del verbo conscribo, que significa consignar por escrito, inscribir en una lista, alistar. Las leyes,

17 Ya en Cicerón (1928) 5,2,3 se hacía mención a esta misma situación. Uno de los intervinientes en el diálogo, Manilio, describe la situación en que se encontraban los particulares, quienes debían acudir al rey para solicitar la declaración del derecho (privado), en cuestiones tales como la delimitación de los campos de cultivo. Para reforzar la idea de la inexistencia de leyes sobre esta clase de materias, Cicerón hace decir a Manilio que al no existir quien cumpliese la función de árbitros, quedaba en manos de los reyes decidir esta clase de problemas ("nec vero quisquam privatus erat disceptator aut arbiter litis, sed omnia conficiebantur iudiciis regiis"). El relato continúa con la afirmación de que el rey Numa Pompilio habría promulgado leyes sobre derecho privado vigentes incluso en época de Cicerón ("qui legum etiam scriptor fuit quas scitis extare).

18 Lantella (1987) p. 224.

19 Así lo ha visto Lantella (1987) p. 224, al sostener que la certeza sería producto de un sistema de mediación, "un sistema di reciproco rispetto in cui l'uno e i molti non si sopraffanno: é pur vero che si parla di leggi reggie, tuttavia, almeno nel caso di Remolo, il re legifera per via comiziale”.

20 La historiografía moderna, en su mayoría se inclina por desechar la posibilidad de que los comicios hayan participado en la gestación de la ley. En tal sentido, De Martino (1972) pp. 155 ss.; Cássola (1989) p. 46 s.; Petrucci (2012) p. 16; Cerami (2010) p. 10 ss., sin aceptar abiertamente la tradición que atribuye a los comicios la función constitucional en comento, exponen razonamientos que hacen atendible a aquella.

21 Sobre si el ius Papirianum es o no coincidente con la lex Papiria, de la que se habla en otras fuentes -punto este que fue afirmado por Paoli- veáse. la opinión contraria de Di PAOLA (1948) pp. 631-651. 
por consiguiente, se encontrarían expuestas en el texto, formando una lista, es decir, una serie o secuencia de normas. Si nos preguntamos, a continuación, por la extensión de esta lista, habrá entonces que poner atención en el uso del adjetivo omnes, de acuerdo al cual se incluirían en ella todas las leyes regias. Y esto lleva a una primera conclusión: en su obra, Papirio no habría realizado selección alguna de leyes, como sería el caso si hubiese registrado solo las vigentes y descartado las que ya no lo fueran. Por el contrario, no hay espacio para otra conclusión más que esta: Papirio debió incluir en su obra todas las leyes regias, sin excepción. Por este motivo, la obra de Sexto Papirio habría adquirido el carácter de recopilación de la totalidad de la producción legislativa de época monárquica.

Más adelante, en una nueva descripción de la obra compiladora de Papirio, Pomponio agrega que este "leges sine ordine latas in unum composuit", es decir, que ha reducido a unidad leyes producidas sin orden. ¿Qué quiere decir, exactamente, con esto Pomponio? Una primera posibilidad es que Papirio haya llevado a cabo su compilación siguiendo un criterio ordenador, de forma de remediar el desorden en el que se encontraban las leyes. Pero no nos indica Pomponio conforme a qué criterio habría realizado Papirio esta labor de reducción a unidad; luego, quedaría abierto el campo para conjeturar un criterio conforme al cual nuestro compilador habría redactado su obra y sería tentador suponer que habría imaginado un orden según la materia objeto de cada ley. Pero me inclino a pensar que una conjetura así tampoco es posible, al menos con base en la tercera característica con que Pomponio describe del trabajo de Papirio: este nada propio habría introducido en el material recopilado ("non quia Papirius de suo quicquam ibi adiecit”), lo que lleva a concluir que ni siquiera se valió Papirio de un criterio de ordenación "externo" al de las condiciones en que se encontraba el material recopilado. Así, una exposición sistemática, según materias o jerarquías, habría podido ser enjuiciada como la introducción de un elemento adicional, ajeno a la propia masa de leyes, originado en el propio Papirio. El texto de Pomponio, por el contrario, no permite tomarse esta libertad.

En definitiva, creo más probable entender que, al describir la obra de Papirio en los términos que lo hace (in unum composuit), Pomponio significa algo bastante más sencillo: que las leyes regias se encontraban dispersas, es decir, que sus textos se encontraban diseminados y que ello, con toda probabilidad, dificultaba su conocimiento. La labor de Papirio -y de ahí su importancia- habría consistido en reunirlas en un solo libro. En mi opinión, la expresión in unum composuit debe ser entendida como "reunidas en un solo texto": tal habría sido el mecanismo conforme al cual se habría operado la reducción a unidad que se destaca en el texto de Pomponio. No creo incompatible con lo dicho conjeturar que la recopilación debió haber seguido un orden cronológico, puesto que este habría sido el único criterio de ordenación "interno" de todo el material recopilado y sería el único que no podría atribuirse al criterio del compilador. La obra de Papirio no sería, por consiguiente, un trabajo de interpretación como tampoco de reorganización del material legislativo, sino solo de reunión de la totalidad del mismo en un solo texto. Su sola aparición supondría, desde ya, un avance, al resolver un problema de incertidumbre causado por la dispersión, con el consecuente desconocimiento o, en el mejor de los casos, el conocimiento solo parcial de los textos. Papirio, entonces, estaba sentando las bases para una comprensión de la legislación regia, es decir, para la creación de ius, lo que en definitiva no ocurriría, como se verá a continuación. 
El cuarto momento histórico, de enorme significación, ahora constitucional, es la expulsión de los reyes (Papirio trabaja, precisamente, en época del último rey, Tarquino el Soberbio), circunstancia que trae aparejada la abolición de toda su legislación ("omnes leges hae exoleverunt"). Ni tan solo una ley se salva, sino que todas padecen el mismo destino, quizá porque son suficientemente conocidas gracias a la obra de Papirio. Desde luego, la obra de este pierde todo su significado, como producto de la abolición de aquellas leyes, de las que constituía su fuente de conocimiento al tiempo que obra de fijación. Permanecerá, de todas formas, su recuerdo en la jurisprudencia posterior, lo que demuestra cómo, a siglos de distancia, aún se valoraba este primer intento por fijar en un solo texto todo el material legislativo.

Pomponio informa que luego de esta abrogación, adviene un nuevo período de incertidumbre, que durará veinte años. En este período el pueblo, por segunda vez, debe hacer uso de un derecho incierto y de algunas costumbres, ya que no de leyes (iterumque coepit populus Romanus incerto magis iure et consuetudine aliqua uti quam per latam legem), hasta que entra en vigor la ley de las XII Tablas. Nuevamente, la incertidumbre causada por la carencia de textos normativos -aunque existían costumbres, parece conjeturable que estas estuviesen basadas en la legislación regia- será resuelta por la aparición de un nuevo texto, ahora más importante. Es interesante, en este punto, complementar el relato de Pomponio con el de Dionisio de Halicarnaso. Desde la perspectiva de este historiador griego, la decisión de poner por escrito las nuevas leyes encuentra su fundamento en el temor que sentían los cónsules Publio Volumnio y Servio Sulpicio Camerino de que el pueblo se rebelara. La razón, según informa Dionisio, se encontraría en una convicción acerca de la estrecha relación entre la igualdad jurídica y la existencia de textos, que había sido difundida por los tribunos: “...pues de nuevo (el pueblo) estaba siendo provocado por los tribunos de la plebe que le enseñaban que el mejor régimen político para hombres libres es la igualdad de derechos, y el pueblo pedía que se administraran los asuntos privados y los públicos de acuerdo con leyes" (Dion.Hal.10,1,1). Y haciendo suya esta idea, el analista griego continúa afirmando: "En esa época todavía no existía entre los romanos ni igualdad de derechos ni de libertad de palabra, ni se habían fijado por escrito todas las cuestiones relativas a la justicia, sino que antiguamente sus reyes dictaban justicia a quienes lo solicitaban, y lo decretado por ellos eso era ley" (Dion. Hal. 10,1,2). La descripción del estado de cosas continúa con la forma en que la justicia era administrada por los cónsules y la imagen que transmite no puede ser peor: "La mayoría de estas decisiones eran acordes con las costumbres de los magistrados, designados para este cargo debido a su rango social. De todas formas, unas pocas resoluciones estaban recogidas en libros sagrados y tenían fuerza de ley, aunque los patricios eran los únicos que las conocían por sus estancias en la ciudad, y en cambio la mayoría de la gente, comerciantes y labradores que bajaban a la ciudad muy esporádicamente para los mercados, todavía las desconocía” (Dion.Hal.10,1,4). El resultado es que la justicia que debían impartir los cónsules dependía de su poder libérrimo para determinar lo justo y ello era una fuente constante de molestias ${ }^{22}$.

De esta forma, la inexistencia de textos, o, al menos, de unos que fuesen conocidos por todos, provocó un estado de cosas en el cual ya no pudo seguir siendo ignorada la de-

22 Sobre el problema de los vicios de la jurisdicción consular, véase HUMBERT (2005) p. 14 s. 
manda de la plebe, de que todos los asuntos, tanto públicos como privados, fuesen llevados de acuerdo con leyes escritas. Estas debían "estar expuestas en el Foro para los magistrados que fueran elegidos cada año y para los particulares, como una delimitación de los mutuos derechos" (Dion. Hal. 10,3,4). De este modo, la existencia de textos no solo cumpliría una función de igualación y superación de la situación de desconocimiento del derecho sino, adicionalmente, una de limitación al poder de los cónsules en su función jurisdiccional.

Así, el relato de Dionisio de Halicarnaso logra poner en juego dos importantes consecuencias relacionadas directamente con la incertidumbre acerca de los principios de justicia de la sociedad romana de esa época: la primera, la desigualdad jurídica; la segunda, el que la resolución jurisdiccional de los conflictos quedase librada al arbitrio de los cónsules, con la consiguiente desprotección ante la arbitrariedad de sus decisiones. El remedio, por consiguiente, era la redacción de las leyes, su exposición en el foro y su aplicación a las controversias. De esta forma, en la medida en que ellas fueran comprendidas por quienes debían aplicarlas, la consecuencia inevitable sería la igualdad de derechos. En su perspectiva, el problema de la incertidumbre del texto se plantea en términos más complejos que en Pomponio, por cuanto el desconocimiento del texto sobre el cual deban resolverse las controversias proyecta sus consecuencias no solo al plano de la certeza, sino, peor aún, al de la desigualdad jurídica.

Queda, finalmente, un problema a resolver: el relativo a aquello que Pomponio refiere como ius incertum. Nuestro jurista hace referencia a él al comienzo y al final de la exposición que hemos analizado y queda por responder si, de acuerdo a su testimonio, la legislación regia resolvió el problema de la incertidumbre del derecho. Todo apuntaría en ese sentido, esto es, a que la incertidumbre del derecho, no ya la de la ley, se habría resuelto. Recuérdense nada más las palabras del mismo Pomponio, al referirse al período inmediatamente posterior a la derogación de la legislación regia, cuando afirma que el pueblo "volvió a regirse por un derecho incierto". Pero esta conclusión debe hacer frente al aparato conceptual que utiliza Pomponio. Si volvemos la mirada a la descripción antes citada de cómo el derecho depende del trabajo de los juristas ("constare non potest ius, nisi sit aliquis iuris peritis, per quem possit cottidie in melius produci”), debiésemos concluir precisamente lo contrario, esto es, que al no existir juristas durante la época de vigencia de las leges regiae, no se habría desarrollado el derecho y, por consiguiente habría continuado siendo incierto. Ya hemos visto que, a juicio de Pomponio, Sexto Papirio nada introdujo en su obra de compilación, ni siquiera criterios para distinguir entre leyes vigentes y derogadas, por lo que difícilmente podría entender que su obra es parangonable con la de los juristas de la época clásica, que es aquella en la cual Pomponio vive. Y aunque así fuese, la intervención de Papirio resulta tan tardía que tampoco serviría para calificar el período de dos siglos o más que le antecede. Estaríamos, por lo tanto, ante un problema provocado por cierto grado de incoherencia en los términos empleados por nuestro jurista. Con todo, creo que una hipótesis es posible. Aunque parece claro que para Pomponio lex y ius son conceptos diferentes, sabemos que no avanza en el sentido de diferenciar la incertidumbre de la ley de la del derecho. Por el contrario, afirma que la derogación de las leyes regias trajo consigo una nueva época de ius incertum, lo que parece avalar la impresión de que confunde uno y otro tipo de incertidumbre. Con todo, podría haber una explicación para ello, y es que Pomponio no se aventura a dar un juicio, porque el caudal de datos de los que dispone es mínimo. 
Tanto lo es, que de todo el período de la monarquía no puede consignar más que lo poco que ahí se lee. A mi juicio, Pomponio solo puede dar cuenta de cómo se resolvió el problema de la incertidumbre de la ley, pero no puede hacer lo propio en relación con el ius. Su silencio al respecto indicaría que efectivamente supone que así fue, pero carece de datos que le permitan afirmarlo y, por consiguiente, se abstiene de hacerlo. Lo que sí parece suponer es que la derogación de las leyes trae consigo la incertidumbre del ius, como lo revela su afirmación según la cual, después de la derogación de la legislación regia coepit populus Romanus incerto magis iure et consuetudine aliqua uti. En otras palabras, me parece claro que para Pomponio la creación de ius supone siempre como punto de partida un texto, un punto cuya negación no es permitida y que constituye la condición de posibilidad de todo desarrollo futuro. Que exista una lex no implica que por modo necesario habrá ius, pero sí constituye el presupuesto de su aparición; la incerteza del ius, consecuencia de la incerteza de la ley, equivale a la inexistencia de condiciones de aparición, no a su desarrollo. De ahí la insistencia en relacionar la falta de producción de leyes con la incerteza del ius.

\section{CONCLUSIONES}

Ya se dijo antes: la certeza es un bien político ${ }^{23}$ cuya importancia sería imposible subestimar. En la dimensión política del problema no solo están incluidos los conflictos de orden social, como podrían serlo las sublevaciones -si recordamos los temores que atribuye Dionisio de Halicarnaso a los decenviros- sino que considera también la pregunta acerca de la relevancia que el texto tiene para la constitución de un sistema jurídico. Difícilmente este puede dar inicio a su desarrollo sin la presencia de textos o fijaciones que den a luz un mínimo de certeza, la que se proyecta sobre los actos que deben ser celebrados al alero de tales textos y a los conflictos que deben ser resueltos conforme a ellos. Sin embargo, la distinción romana entre lex y ius apunta hacia una proyección de mayor calado, que pone de relieve no solo la diferencia fundamental entre el texto y su interpretación (consistente en otros textos) sino en la potencia generadora de esa relación. La narración de Pomponio da a entender con claridad que la acción política de los reyes permitió poner término al problema genéricamente designado como lex incerta, pero no es igualmente claro cuando se trata de responder si, efectivamente, igual fin tuvo el ius incerto. Las leges regiae, que fueron objeto de un trabajo de sistematización, no cristalizaron en un genuino sistema jurídico debido a la falta de un trabajo interpretativo que aportara a su gestación. A partir de la derogación de aquellas la fundación del ius debería soportar todavía otro período de incertidumbre, al que nuevamente se pondría fin por medio de una ley, la decenviral. Pero el ius, aquel que Pomponio quería llamar certo, solo sería posible merced a la interpretación que se haría de aquella norma. Por consiguiente, parece claro que la conservación y el desarrollo de un sistema jurídico dependen en mayor medida de la actividad interpretativa que de la legiferante, por cuanto, si algo puede predicarse de esta última -a partir del texto analizado- es que ni su contenido ni su caudal son suficiente garantía de relevancia y pervivencia.

23 Lantella (1987) p. 224. 


\section{BIBLIOGRAFÍA CITADA}

Bona, Ferdinando (1987): "La certezza del diritto nella giurisprudenza tardo-repubblicana”, en SARgenti, Mario (a cura di), La certezza del diritto nell'esperienza giuridica romana (Padova, Cedam) pp. 101-148.

Bretone, Mario (2011): Diritto romano e coscienza moderna. Dalla tradizione alla storia. (Madrid, Marcial Pons).

Bujulic, Zika (1998): "Leges regiae: pro et contra", Revue Internationale des Droits de l'Antiquité, vol. 45: pp. 89-142.

Cannata, Carlo Augusto (2003): “Iura condere. Il problema della certezza del diritto fra tradizione giurisprudenziale e auctoritas principis”, en Milazzo, Francesco (a cura di), Ius controversum e auctoritas principis (Napoli, Edizioni Scientifiche Italiane) pp. 27-58.

Capogrossi, Luigi - Cássola, Filippo (1990): "Le curie", en Talamanca, Mario (dir.), lineamenti di Storia del diritto romano (Milano, Giuffrè) pp. 43-47.

Cerami, Pietro et al. (2010): Roma e il diritto (Napoli, Jovene).

Cicerón (1928): De re publica (Edinburg, Loeb).

De Martino, Francesco (1972): Storia della costituzione romana, vol. I, (Napoli, Jovene, segunda edición).

Di Paola, Santi (1948): “Dalla 'lex Papiria' al 'ius Papirianum”, en AA.VV., Studi in onore di Siro Solazzi (Napoli, Jovene) pp. 631-651.

GuZMÁn BRITo, Alejandro (2007): Las reglas del 'Código civil' de Chile sobre interpretación de las leyes (Santiago, LexisNexis).

GuZmán Brito, Alejandro (2011): Codificación del derecho civil e interpretación de la leyes (Madrid, Iustel).

Humbert, Michel (2005): “La codificazione decemvirale: tentativo d'interpretazione", en Humbert, Michel (a cura di), Le Dodici Tavole. Dai Decemviri agli Umanisti (Pavia: IUSS Press).

Kunkel, Wolfgang y Schermaier, Martin (2001): Römische Rechtsgeschichte, (Köln, Weimar, Wien, Böhlau, decimotercera edición).

Lantella, Lelio (1987): "Ius certum in D. 1.2.2", en: SARgenti, Mario (a cura di): La certezza del diritto nell'esperienza giuridica romana (Padova, Cedam) pp. 223-229.

Losano, Mario (2002): Sistema e struttura nel diritto, vol. III (Milano, Giuffrè).

Luhmann, Niklas (1987): Rechtssoziologie (Opladen, Westdeutscher Verlag).

Luhmann, Niklas (1995): Das Recht der Gesellschaft (Frankfurt am Main, Suhrkamp, 1995).

Luhmann, Niklas (1998): Complejidad y modernidad: de la unidad a la diferencia (trad. Josetxo Beriain y José María García Blanco, Madrid, Trotta).

Luhmann, Niklas (2005): de: El Derecho de la sociedad (trad. Javier Torres Nafarrate México D.F., Herder, segunda edición).

Paoli, Jules (1946-1947): “Le 'jus Papirianum’ et la loi Papiria”, Revue Historique de Droit Français et Étranger, vol. 24-25: pp. 157-200.

Petrucci, Aldo (2012): Corso di diritto pubblico romano (Torino, Giappichelli). 